Article

\title{
Low Frequency Magnetic Fields Emitted by High-Power Charging Systems
}

\author{
Germana Trentadue ${ }^{1, *}{ }^{-0}$, Rosanna Pinto ${ }^{2, *}$, Marco Zanni ${ }^{1}$, Harald Scholz ${ }^{1}$, \\ Konstantinos Pliakostathis ${ }^{1}$ and Giorgio Martini ${ }^{1}$ \\ 1 European Commission, Joint Research Centre (JRC), (VA) 21027 Ispra, Italy; \\ marco.zanni@ec.europa.eu (M.Z.); Harald.Scholz@ec.europa.eu (H.S.); \\ konstantinos.pliakostathis@ec.europa.eu (K.P.); giorgio.martini@ec.europa.eu (G.M.) \\ 2 ENEA Italian National Agency for New Technologies, Energy and Sustainable Economic Development, \\ (RM) 00123 Casaccia, Italy \\ * Correspondence: trentadue.germana@gmail.com (G.T.); rosanna.pinto@enea.it (R.P.)
}

Received: 26 February 2020; Accepted: 28 March 2020; Published: 1 April 2020

\begin{abstract}
The new generation of fast charging systems faces a formidable technological challenge, aiming to drastically reduce the time needed to recharge an electric vehicle as a way to tackle the range anxiety issue. To achieve this, high power (up to $350 \mathrm{~kW}$ ) is transferred from the grid to the vehicle, leading to potentially high values of low frequency magnetic fields. This study presents the results of measurements of magnetic flux density (B-field) emitted by two different high power charging systems. The electric vehicle used for the recharge was able to digest up to $83 \mathrm{~kW}$ of delivered power. The test procedure was designed to identify the locations where the maximum B-field levels were recorded and to measure the exposure indices according to reference levels for general public exposure defined in the Council Recommendation 1999/519/EC. Measurements in close proximity to the power cabinets during the recharge revealed that, at some points, exposure indices were higher than $100 \%$, leading to the identification of a distance from the system components at which the value was lower than the reference level. In the worst case, this distance was $31 \mathrm{~cm}$.
\end{abstract}

Keywords: electro-mobility; magnetic flux density; high-power charging

\section{Introduction}

Range anxiety is one of the main issues to be tackled to promote a massive deployment of electric vehicles (EVs). One of the approaches consists in increasing battery capacities and building a sufficiently dense network of high-power charging systems (HPCSs) in urban and rural areas. Even though higher driving ranges are still associated with luxury EVs and "supercars", the new generation of HPCSs is already a reality, with 400 charging points foreseen in Europe by the Ionity Consortium no later than 2020 [1]. A HPCS of $350 \mathrm{~kW}$ for instance, typically allows recharging a fast chargeable EV's battery pack of $35 \mathrm{kWh}$ in $10 \mathrm{~min}$. However, this power corresponds to 100 times a normal household power supply, and is supplied in a few minutes and concentrated in a few square meters. Such levels of power imply currents up to approximately $250 \mathrm{~A}_{\mathrm{AC}}$ and $500 \mathrm{~A}_{\mathrm{DC}}$, and produce a magnetic field in the surroundings that should be evaluated to prevent magnetic field exposures exceeding the reference levels (RLs) established for health protection. In Europe, the Council Recommendation 1999/519/EC [2] ensures respect of RLs indicated within the guidelines published by the International Commission on Non-ionizing Radiation Protection (ICNIRP) for general public exposure in 1998 [3]. RLs take into account the evidence of health effects, such as the electrostimulation of nerves at low frequencies (1-10 MHz), and heating within human tissues at higher frequencies (100-300 GHz) [2-4]. Possible 
long-term effects related to a prolonged exposure are not scientifically proven, as confirmed by the World Health Organization [5,6].

The European Interoperability Centre for Electric Vehicles, Smart Homes and Smart Grids (Joint Research Centre (JRC), Ispra, Italy) conducts pre-normative research in line with the European Commission policy priorities in the field of sustainable mobility, including EVs and their recharging infrastructure. In this framework, different investigations of EVs and their interoperability with charging infrastructure are currently conducted, in collaboration with industry, academia, and other research institutions. In 2018, the JRC and the Italian national agency for new technologies, energy, and sustainable economic development (ENEA) began collaboration on these topics with the main objective of contributing to the definition of measurement procedures to assess low frequency magnetic fields emitted by new technologies related to e-mobility. In [7], we presented the results of a test campaign conducted on five $50 \mathrm{~kW}$ DC fast chargers, highlighting the lack of specific measurement procedures for the assessment of magnetic fields generated during conductive recharge within the standard IEC 61851-23 [8]. Magnetic flux density (B-field) peaks at a frequency of $50 \mathrm{~Hz}$ up to above $100 \mu \mathrm{T}$ were recorded during the recharge at full load in close proximity to the charger, while, beyond a distance of $7.5 \mathrm{~cm}$ from the center of the probe, exposure indices were below $50 \%$ of RLs for general public exposure. Furthermore, we highlighted how the approach of the Recommendation 1999/519/EC (based on 1998 ICNIRP guidelines) in the calculation of exposure indices, considering harmonics additive in their effects, is conservative compared to the Weighted Peak Method (WPM) introduced in [9] and implemented within the Directive 2013/35/EU [10], which takes into account the phase and the amplitude of the complex waveforms by weighting with a filter function, based on RLs [9-12]. Two different HPCSs were tested at power levels up to $83 \mathrm{~kW}$, using a vehicle selected among the few that, at the time, were designed to be charged with power above $50 \mathrm{~kW}$. A new joint test campaign, JRC-ENEA, was organized with the aim to improve and refine the procedure already developed to provide reliable data about magnetic fields emitted by these systems during high-power charging, with experimental knowledge about this topic still limited to vehicles and wireless charging [13-19].

\section{Materials and Methods}

Two different HPCSs were tested, while connected to the same fast-chargeable EV, in stand-by and charging conditions. Measurements were performed in the VeLA9 facility (Vehicle electric Laboratory 9), which is part of the Interoperability Center. VeLA9 is a semi-anechoic chamber designed to test electromagnetic compatibility/emissions of vehicles and their charging infrastructure within the frequency range $14 \mathrm{kHz}-18 \mathrm{GHz}$. It is equipped with a shielded chassis dynamometer (four wheels driven) that can reach speeds up to $210 \mathrm{~km} / \mathrm{h}$, with accelerations and regenerative breaking up to $10 \mathrm{~m} / \mathrm{s}^{2}$. The chassis dynamometer is embedded in a turntable with a diameter of $11 \mathrm{~m}$, which allows a 360 degree rotation while the vehicle is driven on the roller bench. In this way, it is possible to test electromagnetic emissions produced by vehicles, as well as their immunity against interference from every position. The facility can also be used to assess the emissions of charging systems during the re-charge by means of a high-power filter of up to $200 \mathrm{~A} /$ phase and up to $440 \mathrm{~V}_{\mathrm{AC}}$.

HPC technology allows DC fast charging up to $350 \mathrm{~kW}$ even if only few EVs currently available on the market are able to digest such high powers. HPCSs support the CCS standard (Combined Charging System) with the possibility to add the option for the CHAdeMO standard in multi-plug devices. The substantial change in the HPC technology, compared to the old generation of $50 \mathrm{~kW}$ fast chargers, consists of the modularity in the power cabinets, which allows customizable charging scenarios. In fact, the transformer and rectification circuitry are generally located in a rack or shielded housing (power unit) separated from the user interface unit, which in turn delivers the converted DC current to the vehicle. Figure 1 shows a scheme typical of this architecture, constituting two power units and the user interface unit. The user interface unit is equipped with adequate connectors and flexible charging cables characterized by an integrated advanced liquid-cooling system, to avoid overheating due to the delivered currents. A single power unit can charge a $400 \mathrm{~V}$ vehicle battery at $150 \mathrm{~kW}$ with an output 
current of $375 \mathrm{~A}$, while two-power cabinet systems can deliver up to $350 \mathrm{~kW}$ and $500 \mathrm{~A}$, being even able to simultaneously charge two EVs. The infrastructure can be enlarged at a later stage, adding more charging points. Furthermore, this dynamic management of the DC output power contributes to saving costs by optimizing the connection to the grid.

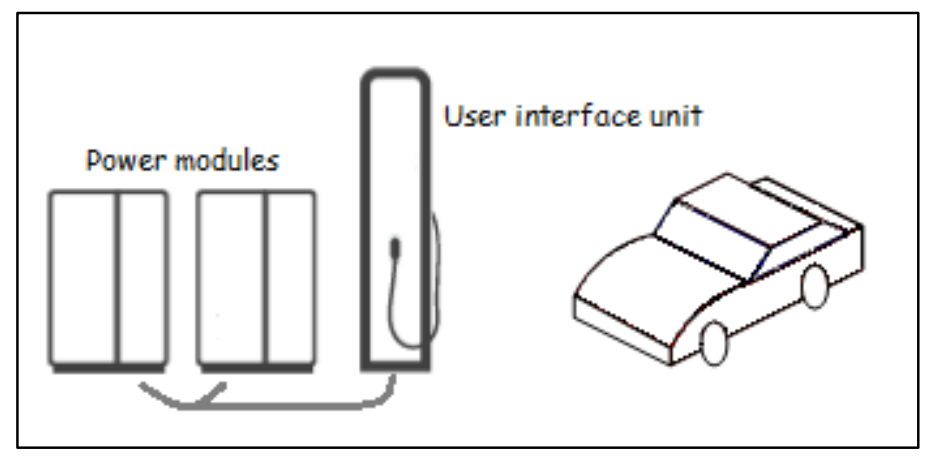

Figure 1. Scheme of a high-power charging system (HPCS).

The main technical specifications of the two tested charging systems are described in Table 1.

Table 1. HPCS main specifications.

\begin{tabular}{|c|c|c|c|c|}
\hline HPCSs & $\begin{array}{c}\text { Electrical } \\
\text { Specifications }\end{array}$ & $\begin{array}{l}\text { Efficiency and } \\
\text { Power Factor }\end{array}$ & $\begin{array}{l}\text { Weight and } \\
\text { Dimensions } \\
(W \times D \times H)\end{array}$ & $\begin{array}{c}\text { Operating } \\
\text { Temperatures }\end{array}$ \\
\hline 1 & $\begin{array}{c}400 \mathrm{~V}_{\mathrm{ac}} \pm 10 \% \\
50 \mathrm{~Hz}, 277 \mathrm{~A} \\
\text { nominal @ } 400 \mathrm{~V}_{\mathrm{ac}} \\
(160 \mathrm{~kW}) ; \mathrm{DC} \\
\text { output: } 500 \mathrm{~A}, \\
150-920 \mathrm{~V} \text { (up to } \\
350 \mathrm{~kW})\end{array}$ & $\begin{array}{l}\geq 94 \% \text { at full load } \\
\quad P F \geq 0.97\end{array}$ & $\begin{array}{l}2 \text { power cabinets } \\
(1340 \mathrm{~kg}, 2030 \times \\
\left.1170 \times 770 \mathrm{~mm}^{3}\right)+ \\
\text { User interface unit } \\
(250 \mathrm{~kg}, 2390 \times 620 \\
\left.\quad \times 440 \mathrm{~mm}^{3}\right)\end{array}$ & $-35{ }^{\circ} \mathrm{C}$ to $+55^{\circ} \mathrm{C}$ \\
\hline 2 & $\begin{array}{c}400 \mathrm{~V}_{\mathrm{ac}} \pm 10 \% \\
50 \mathrm{~Hz} 248 \text { A @ } 172 \\
\text { kVA; DC output: } \\
500 \text { A up to } 640 \mathrm{~V} ; \\
\text { nominal power } \\
322 \mathrm{~kW} @ 920 \mathrm{~V}\end{array}$ & $\begin{array}{c}>95 \% \text { @ full power } \\
\text { PF: } 0.98\end{array}$ & $\begin{array}{l}2 \text { power cabinets } \\
(1100 \mathrm{~kg}, 1000 \times \\
\left.800 \times 1800 \mathrm{~mm}^{3}\right)+ \\
\text { User interface unit } \\
(260 \mathrm{~kg}, 600 \times 300 \\
\left.\quad \times 2400 \mathrm{~mm}^{3}\right)\end{array}$ & $\begin{array}{c}-25 \text { to }+50{ }^{\circ} \mathrm{C} / \\
-35^{\circ} \mathrm{C} \text { to }+50^{\circ} \mathrm{C} \\
\text { (cold option) }\end{array}$ \\
\hline
\end{tabular}

The HPCSs under test were equipped with CCS charging options and connected to the JRC grid providing $440 \mathrm{~V}_{\mathrm{AC}}$, max $200 \mathrm{~A}$. The HPCSs were tested by connecting them to an EV with a declared charging capability up to $100 \mathrm{~kW}$. The distances inside the anechoic chamber between the vehicle under charge, the user interface column, and the two power cabinets, were respectively at least 1 $\mathrm{m}$ and $3 \mathrm{~m}$. Measurements were conducted while charging the vehicle from $10 \%$ to $50 \%$ of its state of charge $(\mathrm{SoC})$, in order to reach a stable delivered power close to maximum achievable charging power $(83 \mathrm{~kW})$. Electrical parameters, such as currents, voltages, and power from the grid and to the EV, were recorded by means of power analyzers (WT 1800, YOKOGAWA Italia srl, Nova Milanese MB, Italy, Sirius-PWR-MCTS2, Dewesoft srl, Roma, Italy). A tri-axial isotropic probe (EHP50G, Narda Safety Test Solutions Cisano sul Neva SV, Italy) was used to detect the B-field within the frequency range $1 \mathrm{~Hz}-400 \mathrm{kHz}$, with a declared resolution of $0.1 \mathrm{nT}$. The instrument is compliant with the standard IEC 61786-1 [20]. Its total declared expanded uncertainty varies between $3 \%$ and $5.3 \%$, depending on the frequency range and on the B-field range (coverage factor $\mathrm{k}=2$, confidence level $95 \%$ ). This takes into account linearity, anisotropy, frequency response, temperature, and relative humidity and includes the contribution of calibration uncertainty [21]. However, the anisotropy contribution measured under our measurement conditions stands around 13\%, leading to an expanded uncertainty of around 19\%. 
Compared to the model used in [7], this model allows the WPM to be applied according to the RLs indicated for general public exposure by ICNIRP 1998 guidelines and implemented in the Council Recommendation 1999/519/EC.

Measurements were performed in the frequency domain within the range from $25 \mathrm{~Hz}$ to $2 \mathrm{kHz}$, aiming to perform a spectrum evaluation considering harmonics additive in their effects (ICNIRP 1998 approach) and, in the time domain, with the WPM accountable for the frequency range $1 \mathrm{~Hz}-400 \mathrm{kHz}$. Both methods lead to the calculation of an index, hereinafter referred to as exposure index (EI) and weighted peak index (WPI), respectively, according to the following Equations (1) and (2).

$$
\begin{gathered}
E I=\sum_{j} \frac{X_{j}}{R L j} \leq 1 \\
W P I=\left|\sum_{i} \frac{A_{i}}{R L_{i}} \cos \left(2 \pi f_{i} t+\theta_{i}+\varphi_{i}\right) \leq 1\right|
\end{gathered}
$$

where, in Equation (1), $X j$ is the field amplitude at frequency $j$, and $R L(X j)$ is the field RL at frequency $j$; in Equation (2), $t$ is time, $A_{i}$ is the amplitude of the $i$ th harmonic component of the field, $R L_{i}$ is the $R L$ at the $i$ th harmonic frequency $f_{i}, \theta_{i}$ is the phase angle of the field, and $\varphi_{i}$ is the phase angle of the filter at the harmonic frequencies. Both indexes were calculated considering RLs of Recommendation 1999/519/EC. If the index value is $\geq 100$ (if expressed in percentage terms), the exposure will be considered not compliant. The measurement procedure, developed in [7], was adopted and improved during the test campaign. Briefly, the B-field actual values and the EIs were measured at a distance of $10 \mathrm{~cm}$ (between the center of the probe and the unit's surface) on a grid of measurement points on each side of the units. The grid was evenly spaced according to the geometry of the unit under test. Figure 2 shows, as an example, the measurement grid used for the two power units and for the user interface unit of HPCS 1.
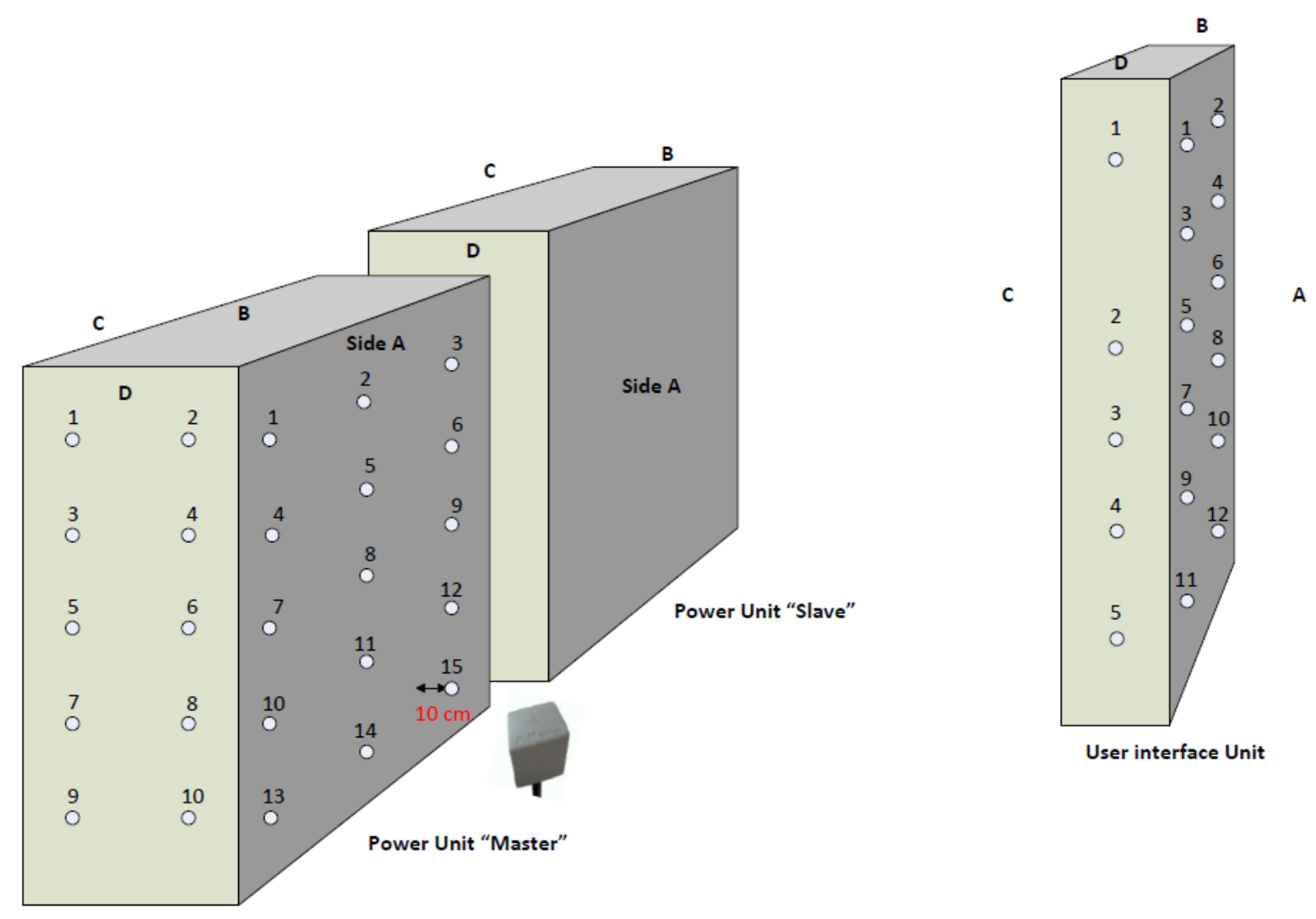

Figure 2. Measurement grid used for HPCS 1. 
In order to ensure maximum repeatability and consistency, all the measurements were performed keeping the same axis direction of the probe with respect to the surface of the system. The positions where EIs values were higher than $100 \%$ were recorded and identified for each unit, and WPIs were measured in each of them. Then, further measurements were executed with a smaller and denser grid surrounding the point where the highest value was measured in order to identify the exact position of the maximum. Once the exact position of the maximum emission point was identified for each unit, additional measurements at a distance of $20 \mathrm{~cm}$ from the maximum were performed. In case of EIs and WPIs $\geq 100 \%$, measurements were repeated to assess the distance at which the indexes were below $100 \%$.

\section{Results}

Different behaviors were observed in terms of power distribution between the two HPCS power cabinets during the recharge. The two units, hereinafter called "master" and "slave", supplied power to the user interface unit and consequently to the recharge either alternately or, in some cases, simultaneously. For HPCS 2, the AC power from the grid was equally distributed between the two power units, and was then converted and transferred to the user interface unit. Regarding HPCS 1 , the power was either concentrated in only one power unit or equally shared between the two power units. According to the manufacturer of HPCS 1, for recharges above $50 \mathrm{~kW}$, the power distribution between the two units depended on internal algorithms, which involved different variables, such as service hours and temperature, and was not easily predictable. Figure 3 shows the measured power and current on the AC and DC side of HPCS 1 slave during a recharge at full load from $10 \%$ to $57 \%$ of the vehicle SoC, related to data of Table 2. AC current values were between 127 and $132 \mathrm{~A}$, while DC current was stable, close to $200 \mathrm{~A}$. As shown, this part of the recharge $(10 \%-50 \%$ of SoC), where values were stable, lasted more than $20 \mathrm{~min}$. In order to guarantee similar conditions, measurements were performed within this 20 min time interval, keeping the AC current stable within the range 127-132 A and the delivered power above $80 \mathrm{~kW}$.

The following tables show the measurements for each HPCS during full load recharges on the two power cabinets at a distance of $10 \mathrm{~cm}$ from the center of the probe according to the defined grid. The values are displayed in terms of wideband values of the B-field within the frequency range from $25 \mathrm{~Hz}$ to $2 \mathrm{kHz}$ and, in terms of EIs, calculated according to the Recommendation 1999/519/EC. Tables 2 and 3 refer to the case when the two power units (slave and master) of HPCS 1 operated alternately. EIs $\geq 100 \%$ are displayed in bold.
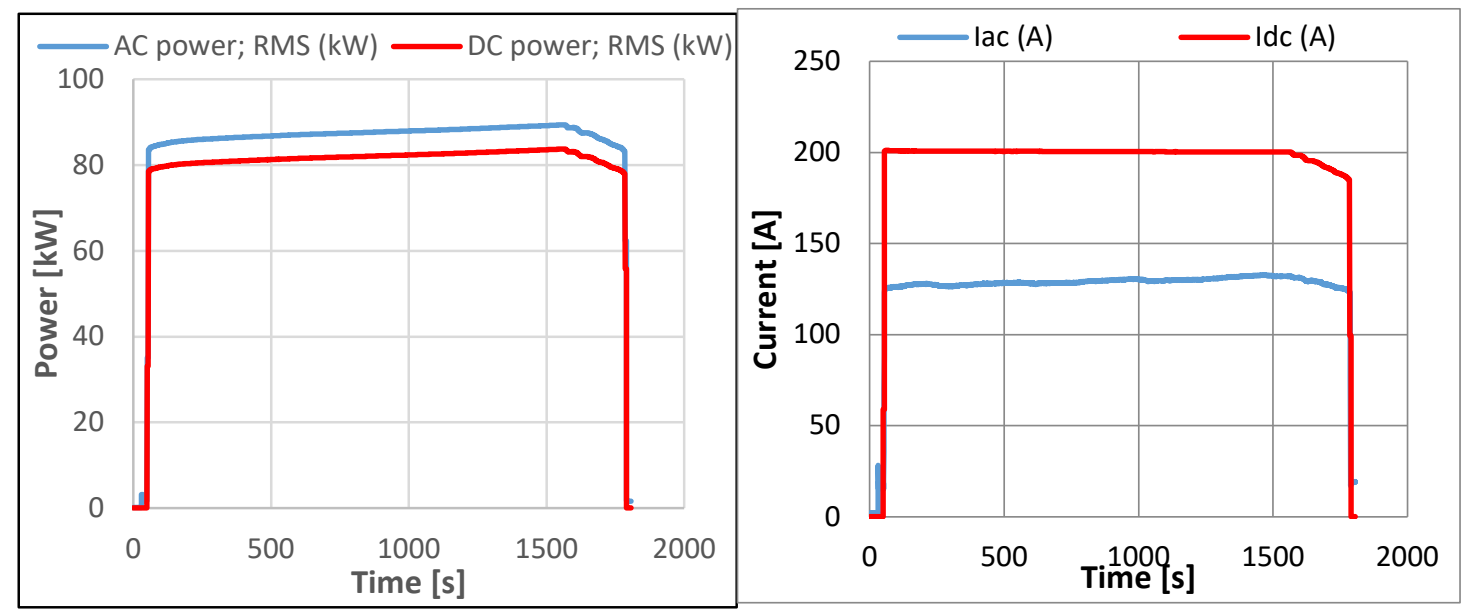

Figure 3. AC and DC power and current during a recharge (HPCS 1 slave, Table 2 measurements). 
Table 2. B-field and exposure indexes (EIs) according to the measurement grid for the power unit slave, HPCS 1.

\begin{tabular}{|c|c|c|c|c|c|c|c|c|}
\hline \multirow{2}{*}{$\begin{array}{c}\text { Side } \\
\text { Positions }\end{array}$} & \multicolumn{2}{|l|}{ A } & \multicolumn{2}{|l|}{ B } & \multicolumn{2}{|l|}{$C$} & \multicolumn{2}{|l|}{$\mathrm{D}$} \\
\hline & B $(\mu \mathrm{T})$ Wide Band & EI \% & B $(\mu \mathrm{T})$ Wide Band & EI \% & B $(\mu \mathrm{T})$ Wide Band & EI \% & B $(\mu \mathrm{T})$ Wide Band & EI \% \\
\hline 1 & 3.40 & 19.86 & 4.56 & 36.06 & 4.64 & 21.10 & 4.21 & 13.84 \\
\hline 2 & 3.35 & 19.22 & 5.78 & 40.31 & 4.46 & 19.93 & 4.38 & 12.96 \\
\hline 3 & 4.10 & 22.74 & 8.41 & 57.81 & 4.68 & 23.78 & 8.96 & 26.21 \\
\hline 4 & 7.11 & 36.05 & 12.99 & 77.62 & 14.45 & 59.23 & 9.51 & 25.89 \\
\hline 5 & 6.31 & 38.55 & 23.03 & 121.6 & 12.50 & 46.64 & 20.91 & 61.15 \\
\hline 6 & 7.79 & 42.43 & 46.26 & 213.9 & 10.62 & 51.7 & 21.29 & 67.38 \\
\hline 7 & 21.11 & 150.9 & 26.13 & 162.5 & 64.59 & 308.5 & 27.55 & 132.2 \\
\hline 8 & 31.41 & 269.8 & 38.29 & 305.5 & 61.92 & 251.0 & 27.22 & 122.5 \\
\hline 9 & 26.49 & 208.3 & 31.21 & 128.3 & 33.23 & 230 & 39.86 & 146.2 \\
\hline 10 & 28.75 & 313.2 & 34.18 & 159.9 & 56.76 & 578.2 & 28.83 & 98.9 \\
\hline 11 & 48.74 & 382.6 & & & 44.81 & 390.2 & & \\
\hline 12 & 30.13 & 351.4 & & & 37.02 & 464.4 & & \\
\hline 13 & 39.24 & 240.9 & & & 61.17 & 322.5 & & \\
\hline 14 & 58.75 & 237.2 & & & 60.53 & 244.4 & & \\
\hline 15 & 24.74 & 176.4 & & & 46.03 & 404.2 & & \\
\hline
\end{tabular}

Table 3. B-field and EIs according to the measurement grid for the power unit master, HPCS 1.

\begin{tabular}{|c|c|c|c|c|c|c|c|c|}
\hline \multirow{2}{*}{$\begin{array}{c}\text { Side } \\
\text { Positions }\end{array}$} & \multicolumn{2}{|l|}{$\mathbf{A}$} & \multicolumn{2}{|l|}{ B } & \multicolumn{2}{|l|}{$\mathrm{C}$} & \multicolumn{2}{|l|}{ D } \\
\hline & B $(\mu \mathrm{T})$ Wide Band & EI \% & B $(\mu \mathrm{T})$ Wide Band & EI \% & B $(\mu \mathrm{T})$ Wide Band & EI \% & B $(\mu \mathrm{T})$ Wide Band & EI \% \\
\hline 1 & 3.53 & 20.33 & 4.23 & 40.45 & 4.94 & 27.59 & 3.44 & 15.54 \\
\hline 2 & 4.00 & 22.24 & 5.34 & 45.39 & 4.70 & 25.76 & 3.88 & 16.65 \\
\hline 3 & 4.20 & 22.99 & 10.07 & 60.95 & 4.67 & 27.32 & 6.91 & 26.46 \\
\hline 4 & 10.13 & 54.63 & 17.06 & 77.2 & 14.73 & 63.56 & 7.59 & 26.63 \\
\hline 5 & 11.25 & 73.22 & 30.59 & 138.2 & 13.50 & 51.48 & 23.10 & 64.14 \\
\hline 6 & 11.12 & 69.30 & 57.10 & 218.4 & 12.25 & 56.60 & 23.07 & 64.0 \\
\hline 7 & 26.66 & 202.9 & 28.71 & 153.5 & 75.28 & 309.4 & 24.60 & 118.9 \\
\hline 8 & 43.88 & 383.4 & 35.91 & 200.5 & 70.54 & 258.6 & 23.48 & 114.1 \\
\hline 9 & 25.31 & 318.6 & 44.05 & 158.8 & 33.12 & 219.2 & 35.08 & 136.0 \\
\hline 10 & 39.42 & 418.2 & 49.45 & 201.5 & 64.14 & 551.6 & 21.39 & 110.9 \\
\hline 11 & 45.89 & 382.8 & & & 52.11 & 455.8 & & \\
\hline 12 & 39.74 & 454.2 & & & 43.25 & 400.4 & & \\
\hline 13 & 34.52 & 255.0 & & & 64.38 & 326.0 & & \\
\hline 14 & 36.31 & 205.6 & & & 83.83 & 312.6 & & \\
\hline 15 & 28.00 & 215.5 & & & 49.87 & 440.9 & & \\
\hline
\end{tabular}

Tables 4 and 5 are related to HPCS 2 whose behavior consisted of an equal sharing of the power between the two units.

Table 4. B-field and EIs according to the measurement grid for the power unit master, HPCS 2.

\begin{tabular}{|c|c|c|c|c|c|c|c|c|}
\hline \multirow{2}{*}{$\begin{array}{c}\text { Side } \\
\text { Positions }\end{array}$} & \multicolumn{2}{|l|}{$\mathbf{A}$} & \multicolumn{2}{|l|}{ B } & \multicolumn{2}{|l|}{$\mathrm{C}$} & \multicolumn{2}{|l|}{ D } \\
\hline & B $(\mu \mathrm{T})$ Wide Band & EI \% & B $(\mu \mathrm{T})$ Wide Band & EI \% & B $(\mu \mathrm{T})$ Wide Band & EI \% & B $(\mu \mathrm{T})$ Wide Band & EI \% \\
\hline 1 & 2.57 & 10.51 & 1.56 & 6.65 & 2.163 & 6.96 & 1.36 & 5.28 \\
\hline 2 & 1.53 & 6.78 & 1.40 & 6.28 & 1.86 & 5.50 & 1.97 & 6.86 \\
\hline 3 & 1.81 & 7.26 & 1.45 & 7.91 & 2.49 & 10.56 & 2.44 & 7.76 \\
\hline 4 & 2.74 & 12.98 & 3.10 & 9.92 & 4.20 & 13.76 & 3.24 & 17.45 \\
\hline 5 & 2.89 & 11.58 & 2.16 & 5.99 & 3.38 & 10.26 & 6.85 & 22.75 \\
\hline 6 & 3.44 & 10.61 & 2.81 & 10.41 & 3.91 & 15.52 & 4.11 & 14.33 \\
\hline 7 & 3.38 & 8.69 & 6.44 & 19.26 & 20.27 & 57.22 & 11.09 & 42.43 \\
\hline 8 & 8.41 & 24.65 & 8.78 & 16.53 & 20.53 & 53.14 & 9.17 & 54.74 \\
\hline 9 & 9.09 & 24.87 & 8.80 & 26.90 & 22.55 & 73.13 & 7.44 & 29.31 \\
\hline 10 & 20.40 & 60.68 & 13.14 & 30.52 & 38.09 & 92.98 & 20.54 & 54.91 \\
\hline 11 & 16.33 & 43.95 & 40.11 & 72.16 & 28.44 & 57.60 & 25.71 & 68.58 \\
\hline 12 & 12.57 & 40.40 & 30.09 & 77.47 & 30.74 & 80.89 & 15.19 & 34.26 \\
\hline 13 & 14.90 & 56.36 & 16.93 & 40.00 & 35.32 & 92.59 & 13.93 & 37.76 \\
\hline 14 & 18.17 & 63.60 & 26.68 & 53.76 & 48.63 & 115.3 & 29.34 & 69.51 \\
\hline 15 & 14.52 & 49.64 & 25.9 & 70.83 & 44.79 & 130.9 & 15.44 & 49.70 \\
\hline
\end{tabular}


Table 5. B-field and EIs according to the measurement grid for the power unit slave, HPCS 2.

\begin{tabular}{|c|c|c|c|c|c|c|c|c|}
\hline Side & $\mathbf{A}$ & & B & & $\mathrm{C}$ & & D & \\
\hline Positions & B $(\mu \mathrm{T})$ Wide Band & EI \% & B $(\mu \mathrm{T})$ Wide Band & EI \% & B $(\mu \mathrm{T})$ Wide Band & EI \% & B $(\mu \mathrm{T})$ Wide Band & EI \% \\
\hline 1 & 1.93 & 8.59 & 1.78 & 6.14 & 2.20 & 6.16 & 1.34 & 9.42 \\
\hline 2 & 1.31 & 6.25 & 1.6 & 6.16 & 1.81 & 5.12 & 2.41 & 11.68 \\
\hline 3 & 1.55 & 5.70 & 1.5 & 7.60 & 1.96 & 6.49 & 1.66 & 7.07 \\
\hline 4 & 2.78 & 12.46 & 4.01 & 11.52 & 3.96 & 12.51 & 2.88 & 13.90 \\
\hline 5 & 3.43 & 12.22 & 3.10 & 7.77 & 3.51 & 8.87 & 4.81 & 15.35 \\
\hline 6 & 3.67 & 9.55 & 3.97 & 15.25 & 3.45 & 11.28 & 3.26 & 11.71 \\
\hline 7 & 17.47 & 43.22 & 9.86 & 24.06 & 17.79 & 51.82 & 10.9 & 36.83 \\
\hline 8 & 11.36 & 28.51 & 11.72 & 21.23 & 17.16 & 45.01 & 9.82 & 54.90 \\
\hline 9 & 10.38 & 23.90 & 11.98 & 36.70 & 21.79 & 60.71 & 9.83 & 31.20 \\
\hline 10 & 13.82 & 41.31 & 12.84 & 28.96 & 27.97 & 74.14 & 23.94 & 60.22 \\
\hline 11 & 12.66 & 36.88 & 34.61 & 67.98 & 20.0 & 56.39 & 19.07 & 42.94 \\
\hline 12 & 11.54 & 28.77 & 23.49 & 71.29 & 26.54 & 72.37 & 12.06 & 40.44 \\
\hline 13 & 7.82 & 35.14 & 15.64 & 39.12 & 46.9 & 123.3 & 28.60 & 81.26 \\
\hline 14 & 8.94 & 31.86 & 37.99 & 79.04 & 34.04 & 101.5 & 31.94 & 73.73 \\
\hline 15 & 9.03 & 32.11 & 35.13 & 82.98 & 35.02 & 117.0 & 12.34 & 47.13 \\
\hline
\end{tabular}

The B-field had its highest peaks at a frequency of $50 \mathrm{~Hz}$ but measured values were always below $100 \mu \mathrm{T}$ (RL for general public exposure at $50 \mathrm{~Hz}$, established in the Recommendation 1999/519/EC). Even though each spectral component is below the RL curve, EIs higher than 100\% were recorded. Furthermore, the point where the maximum EI was recorded does not always correspond to the point of maximum B-field (e.g., Table 2 side C, position 7, max B: $64.59 \mu \mathrm{T}$, EI: 308.5\%; position 10, max EI $578.2 \%$, B: $56.76 \mu \mathrm{T})$. Among these occurrences, there were points where EIs exceeded the RLs by up to five times (e.g., Tables 2 and 3, position 10).

Table 6 refers to the further analysis performed according to the protocol, in the positions where RLs were exceeded for HPCS 1 power unit master. It shows a comparison between EIs and WPIs. In these points, WPIs are lower than the EIs, confirming that the approach of the EI, recommended in [2] for the assessment of general public exposure, is rather conservative.

Table 6. HPCS 1 power unit master: comparison between EIs and weighted peak indexes (WPIs).

\begin{tabular}{|c|c|c|c|c|c|c|c|c|c|c|c|c|}
\hline \multirow{2}{*}{$\begin{array}{c}\text { Side } \\
\text { Positions }\end{array}$} & \multicolumn{3}{|c|}{ A } & \multicolumn{3}{|c|}{ B } & \multicolumn{3}{|c|}{ C } & \multicolumn{3}{|c|}{ D } \\
\hline & EI \% & WPI \% & EI/WPI & EI \% & WPI \% & EI/WPI & EI \% & WPI \% & EI/WPI & EI \% & WPI \% & EI/WPI \\
\hline 5 & & & & 138.2 & 67.5 & 2.05 & & & & & & \\
\hline 6 & & & & 218.4 & 98.8 & 2.21 & & & & & & \\
\hline 7 & 202.9 & 92.6 & 2.19 & 153.5 & 75.3 & 2.04 & 309.4 & 153.8 & 2.01 & 118.9 & 68.0 & 1.75 \\
\hline 8 & 383.4 & 201.2 & 1.91 & 200.5 & 96.3 & 2.08 & 258.6 & 106.0 & 2.44 & 114.1 & 55.1 & 2.07 \\
\hline 9 & 318.6 & 168.8 & 1.89 & 158.8 & 77.8 & 2.04 & 219.2 & 97.7 & 2.24 & 136.0 & 91.2 & 1.49 \\
\hline 10 & 418.2 & 291.6 & 1.43 & 201.5 & 93.1 & 2.16 & 551.6 & 319.8 & 1.72 & 110.9 & 50.2 & 2.21 \\
\hline 11 & 382.8 & 160.4 & 2.39 & & & & 455.8 & 263.9 & 1.73 & & & \\
\hline 12 & 454.2 & 288.9 & 1.57 & & & & 400.4 & 185.6 & 2.16 & & & \\
\hline 13 & 255.0 & 152.5 & 1.67 & & & & 326.0 & 153.7 & 2.12 & & & \\
\hline 14 & 205.6 & 113.0 & 1.82 & & & & 312.6 & 139.2 & 2.25 & & & \\
\hline 15 & 215.5 & 148.1 & 1.46 & & & & 440.9 & 226.3 & 1.95 & & & \\
\hline
\end{tabular}

In some cases, (e.g., side B and side D), EIs were above the RLs, while WPIs were below. However, for side A (positions 8-15) and C (positions 7-15) WPIs were between one and three times greater than the compliance value (position 10).

The ratios between EI and WPI (EI/WPI) give the impression of how much the EIs were conservative compared to WPI. Values are between 2.44 (Side C, position 8) and 1.43 (Side A, position 10). These values depend on the harmonic content of the resulting field in that position and demonstrate the importance of taking into account phase angles of the field at the harmonic frequencies in case of a complex waveform. 
Table 7 shows the characterization of the points where maximum emission was assessed in both HPCSs at different distances between the power unit surface and the center of the probe $(10 \mathrm{~cm}$ and $20 \mathrm{~cm}$ ). In the case of HPCS 1, the point of maximum emission is located on the left of side C in the surroundings of position 10 for both power units. In case of power equally distributed between the two cabinets (same current flowing into the master and the slave), the B-field proportionally decreases. Both EIs and WPIs also decrease, but remain above 100\%. For HPCS 2, a single point of maximum was identified close to position 15 of side $C$ for both the power units master and slave. EIs were slightly higher than $100 \%$, while WPIs were always below.

Table 7. Characterization of the points of maximum emissions for HPCSs 1 and 2.

\begin{tabular}{ccccc}
\hline Power Unit & Distance & B $(\boldsymbol{\mu}$ T) Wide Band & EI \% & WPI \% \\
\hline HPCS 1 POWER & $10 \mathrm{~cm}$ & 64.68 & 576.89 & 346.86 \\
UNIT MASTER & $\begin{array}{c}10 \mathrm{~cm} \text { (power } \\
\text { equally shared) }\end{array}$ & 36.95 & 347.1 & 197.23 \\
& $20 \mathrm{~cm}$ & 24.67 & 220.6 & 110.22 \\
\hline HPCS 1 POWER & $10 \mathrm{~cm}$ & 57.51 & 611.16 & 381.46 \\
UNIT SLAVE & $10 \mathrm{~cm}$ (power & 34.09 & 325.53 & 186.14 \\
& $20 \mathrm{~cm}$ & 29.28 & 255.58 & 174.16 \\
\hline HPCS 2 POWER & $10 \mathrm{~cm}$ & 55.11 & 127.24 & 73.88 \\
UNIT MASTER & $20 \mathrm{~cm}$ & 16.23 & 44.77 & 31.99 \\
HPCS 2 POWER & $10 \mathrm{~cm}$ & 45.63 & 108.34 & 65.53 \\
UNIT SLAVE & $20 \mathrm{~cm}$ & 16.23 & 49.67 & 32.66 \\
\hline
\end{tabular}

The difference in behavior between the two systems could be explained analyzing their internal circuitry architecture and composition, but this is out of the scope of this article. Table 8 indicates the distance at which the EIs and WPIs became lower than $100 \%$.

Table 8. Distance of compliance according to WPI and EI.

\begin{tabular}{cccc}
\hline & Power Unit & \multicolumn{2}{c}{ Distance of Compliance (cm) } \\
\hline & & WPI & EI \\
\cline { 2 - 4 } & Master & 23 & 31 \\
\cline { 2 - 4 } HPCS 1 & Slave & 22.5 & 31.5 \\
& $\begin{array}{c}\text { Master } \\
\text { (power equally shared) }\end{array}$ & 14 & 26 \\
\cline { 2 - 4 } & $\begin{array}{c}\text { Slave } \\
\text { (power equally shared) }\end{array}$ & 10 & 23 \\
\hline \multirow{2}{*}{ HPCS 2 } & Master & $<10$ & 13 \\
\cline { 2 - 4 } & Slave & $<10$ & 14 \\
\hline
\end{tabular}

The compliance distances presented in Table 8 are affected by the measurement uncertainty (about 19\%) and by the geometry of the measurement probe. Unfortunately, it is not possible to quantitatively assess the weight of these elements on the compliance distance uncertainty, due to the high non-uniformity of the magnetic field in the near field condition. For this reason, it may be correct to consider a safe margin of a few centimeters, if a zoning of the charger become necessary.

Concerning the user interface unit, the delivered current was DC, so that B-field values within the investigated frequency range were not expected to be high. Indeed, the wideband maximum value measured with dedicated measurement grids according to the geometry of the columns at a distance of $10 \mathrm{~cm}$ from the center of the probe during the $83 \mathrm{~kW}$ recharge for HPCS 1 did not exceed $3 \mu \mathrm{T}$, with associated EI and WPI equal to $22.7 \%$ and $12.9 \%$, respectively. These values were measured on the 
back part of the column (side C). For HPCS 2, values were extremely low: the maximum wideband B-field ( $25 \mathrm{~Hz}$ to $2 \mathrm{kHz}$ ) was $0.6 \mu \mathrm{T}$, recorded on side B, and the EI and WPI were $1.6 \%$ and of $7.3 \%$, respectively. Table 9 summarizes the results for HPCS 1 side C and HPCS 2 side B. Standby values were below $0.2 \mu \mathrm{T}$ for both HPCSs.

Table 9. User interface unit: EIs and WPIs for HPCS 1 side C and HPCS 2 side B.

\begin{tabular}{ccccc}
\hline & \multicolumn{2}{c}{ HPCS 1 Side C } & \multicolumn{2}{c}{ HPCS 2 Side B } \\
\hline Positions & EI \% & WPI \% & EI \% & WPI \% \\
\hline 1 & 0.44 & 1.36 & 1.00 & 7.84 \\
2 & - & 1.16 & 1.60 & 7.27 \\
3 & 3.36 & 2.84 & 0.02 & 1.99 \\
4 & 1.07 & 2.82 & 1.70 & 2.02 \\
5 & 5.44 & 3.45 & 0.99 & 1.77 \\
6 & 8.67 & 5.14 & & \\
7 & 14.59 & 7.22 & & \\
8 & 22.73 & 12.89 & & \\
9 & 21.22 & 6.34 & & \\
10 & 15.76 & 8.88 & & \\
11 & 3.47 & 3.13 & & \\
12 & 0.44 & 3.90 & & \\
\hline
\end{tabular}

\section{Conclusions}

The new generation of HPCSs promises recharging times of about $10 \mathrm{~min}$, the possibility of simultaneous recharges of more than one EV, modularity, high efficiency, and optimization of the grid connection and, consequently, of the costs of overall energy consumption. The new architecture of the tested systems already shows its remarkable potential in terms of flexibility and modularity. In this paper, the procedure, already developed within the framework of the JRC-ENEA collaboration, was refined and improved to provide reliable data about low frequency magnetic fields emitted by these systems to pave the way for future normative development. An EV, theoretically chargeable up to $100 \mathrm{~kW}$ and commercially available, was charged with two HPCSs. During the recharge at full load, the B-field was measured around the power units and the user interface unit according to a defined grid. Once the location at which the maximum recorded value was identified, further measurements were performed at a distance of $20 \mathrm{~cm}$ from the maximum, and, in the case of values above RLs, a compliance distance derived. Results obtained for HPCS 2 do not give rise to safety concerns, as the majority of the B-field values were below RLs, especially in the surroundings of the user interface column, where the maximum encountered value was less than $0.1 \mu \mathrm{T}$. However, for one of the two HPCSs, 28 out of 50 measurement points at a distance of $10 \mathrm{~cm}$ from the center of the probe recorded EIs more than two times greater than $100 \%$. At 16 of these points, the WPI was also above $100 \%$. For HPCS 2 , the distance from the power cabinet surface at which EIs were all below $100 \%$ was $14 \mathrm{~cm}$, while for HPCS 1 the compliance distance was $23 \mathrm{~cm}$ considering WPI, and $31 \mathrm{~cm}$ considering EI, in the case of power units operating alternately. It is worth highlighting that the maximum achievable power in our study was $83 \mathrm{~kW}$ for a recharge of a single vehicle, while each power unit was able to singularly supply up to $175 \mathrm{~kW}$ for a total of $350 \mathrm{~kW}$ for the HPCS. More powerful and higher performance vehicles with higher battery capabilities, and the possibility of multiple simultaneous recharges may lead to different possible future scenarios that should be fully explored. However, under these conditions, the new architecture comes in handy considering that a carefully planned arrangement of power cabinets may avoid potential safety issues, especially for people wearing electronic medical devices. Future scenarios may include urban recharge stations with hundreds of HPCSs. These spaces should be properly designed by isolating power cabinets in separated areas and by guaranteeing an appropriate safety distance from public areas. 
Author Contributions: Conceptualization, G.T., R.P., G.M.; methodology, G.T., R.P.; investigation, G.T., M.Z., K.P.; resources, H.S., G.M.; All authors have read and agreed to the published version of the manuscript. Authorship must be limited to those who have contributed substantially to the work reported.

Funding: This research received no external funding.

Acknowledgments: Authors would like to express their special thanks of gratitude to A. Bonamin and M. Centurelli for their constant support to the technical activities. ENEA participation to this work was in the framework of the "Research on the Electric System", a multiannual research Programme funded by the Italian Ministry of the Economic Development.

Conflicts of Interest: The authors declare no conflict of interest.

\section{References}

1. Spöttle, M.; Jörling, K.; Schimmel, M.; Staats, M.; Grizzel, L.; Jerram, L.; Drier, W.; Gartner, J. Research for TRAN Committee-Charging Infrastructure for Electric Road Vehicles; Policy Department for Structural and Cohesion Policies: Brussels, Belgium, 2018.

2. European Commission (EC). 1999/519/EC Council recommendation of 12 July 1999 on the limitation of exposure of the general public to electromagnetic fields (0 Hz to $300 \mathrm{GHz})$. Off. J. Eur. Communities 1999, 199, 59-70.

3. International Commission on Non-Ionizing Radiation Protection (ICNIRP). Guidelines for limiting exposure to time varying electric, magnetic and electromagnetic fields (up to $300 \mathrm{GHz}$ ). Health Phys. 1998, 74, 494-522.

4. Samaras, T.; Leitgeb, N.; Auvinen, A.; Danker-Hopf, H.; Mattsso, M.-O.; Norppa, H.; Rubin, G.J.; Scarfí, M.R.; Schüz, J.; Sienkiewicz, Z.; et al. SCENIHR (Scientific Committee on Emerging and Newly Identified Health Risks), Potential Health Effects of Exposure to Electromagnetic Fields (EMF), 27 January, 2015; European Commission DG SANTE: Luxembourg, 2015.

5. World Health Organization (WHO). Environmental Health Criteria 238: Extremely Low Frequency Fields; WHO: Geneva, Switzerland, 2007.

6. Repacholi, M. Concern that "EMF" magnetic fields from power lines cause cancer. Sci. Total. Environ. 2012, 426, 454-458. [CrossRef] [PubMed]

7. Trentadue, G.; Pinto, R.; Salvetti, M.; Zanni, M.; Pliakostathis, K.; Scholz, H.; Martini, G. Assessment of Low-Frequency Magnetic Fields Emitted by DC Fast Charging Columns. Bioelectromagnetics 2020. [CrossRef] [PubMed]

8. International Electrotechnical Commission (IEC). IEC 61851-23 Electric Vehicle Conductive Charging System-Part 23: DC Electric Vehicle Charging Station; IEC: Geneva, Switzerland, 2014.

9. International Commission on Non-Ionizing Radiation Protection (ICNIRP). Guidelines for limiting exposure to time-varying electric and magnetic fields (1 Hz TO $100 \mathrm{kHz}$ ). Health Phys. 2010, 99, 818-836.

10. European Union (EU). Directive 2013/35/EU of the European Parliament and of the Council of 26 June 2013 on the minimum health and safety requirements regarding the exposure of workers to the risks arising from physical agents (electromagnetic fields). Off. J. Eur. Union 2013, 2013, 1-21.

11. International Commission on Non-Ionizing Radiation Protection (ICNIRP). Guidance on determining compliance of exposure to pulsed fields and complex non-sinusoidal waveforms below $100 \mathrm{kHz}$ with ICNIRP guidelines. Health Phys. 2003, 84, 383-387. [CrossRef] [PubMed]

12. Crotti, G.; Giordano, D. Analysis of critical situations in the evaluation of human exposure to magnetic fields with complex waveforms. Radiat. Prot. Dosim. 2009, 137, 227-230. [CrossRef] [PubMed]

13. Hareuveny, R.; Sudan, M.; Halgamuge, M.N.; Yaffe, Y.; Tzabari, Y.; Namir, D.; Kheifets, L.I. Characterization of Extremely Low Frequency Magnetic Fields from Diesel, Gasoline and Hybrid Cars under Controlled Conditions. Int. J. Environ. Res. Public Health 2015, 12, 1651-1666. [CrossRef] [PubMed]

14. Karabetsos, E.; Kalampaliki, E.; Koutounidis, D. Testing Hybrid Technology Cars: Static and Extremely Low-Frequency Magnetic Field Measurements. IEEE Veh. Technol. Mag. 2014, 9, 34-39. [CrossRef]

15. Concha, P.M.-T.; Velez, P.; Lafoz, M.; Arribas, J.R.; Moreno-Torres, P. Passenger Exposure to Magnetic Fields due to the Batteries of an Electric Vehicle. IEEE Trans. Veh. Technol. 2015, 65, 4564-4571. [CrossRef]

16. Tell, R.A.; Sias, G.; Smith, J.; Sahl, J.; Kavet, R. ELF magnetic fields in electric and gasoline-powered vehicles. Bioelectromagnetics 2012, 34, 156-161. [CrossRef] [PubMed] 
17. Vassilev, A.; Ferber, A.; Wehrmann, C.; Pinaud, O.; Schilling, M.; Ruddle, A.R. Magnetic Field Exposure Assessment in Electric Vehicles. IEEE Trans. Electromagn. Compat. 2014, 57, 35-43. [CrossRef]

18. Carlson, R.; Normann, B. Test results of the PLUGLESS ${ }^{\mathrm{TM}}$ inductive charging system from Evatran Group, Inc. SAE Int. J. Altern. Powertrains 2014, 3, 64-71. [CrossRef]

19. Campi, T.; Cruciani, S.; Maradei, F.; Feliziani, M. Magnetic Field during Wireless Charging in an Electric Vehicle According to Standard SAE J2954. Energies 2019, 12, 1795. [CrossRef]

20. International Electrotechnical Commission (IEC). IEC 61786-1 Measurement of DC Magnetic, AC Magnetic, and AC Electric Fields from $1 \mathrm{~Hz}$ to $100 \mathrm{kHzwith}$ Regard to Exposure of Human Beings_Part 1: Requirements for Measuring Instruments; IEC: Geneva, Switzerland, 2013.

21. Narda Safety Test Solutions. User's Manual EHP-50G Electric and Magnetic Field Probe_Analyzer from 1 Hz up to $400 \mathrm{kHz}$; Narda Safety Test Solutions: Segrate, Italy, 2016.

(C) 2020 by the authors. Licensee MDPI, Basel, Switzerland. This article is an open access article distributed under the terms and conditions of the Creative Commons Attribution (CC BY) license (http://creativecommons.org/licenses/by/4.0/). 